\title{
Correction: A rapid multiplex PCR assay for presumptive species identification of rhinoceros horns and its implementation in Vietnam
}

Kyle M. Ewart, Greta J. Frankham, Ross McEwing, Dang Tat The, Carolyn J. Hogg, Claire Wade, Nathan Lo, Rebecca N. Johnson

There are errors in Table 1. The amplicon lengths for primers RID_FWD/RID_REV and Mac_FWD/Mac_REV do not include primer regions. Please see the corrected Table 1 here.

Citation: Ewart KM, Frankham GJ, McEwing R, The DT, Hogg CJ, Wade C, et al. (2018) Correction: A rapid multiplex PCR assay for presumptive species identification of rhinoceros horns and its implementation in Vietnam. PLOS ONE 13(8): e0202433. https://doi.org/10.1371/journal. pone. 0202433

Published: August 10, 2018

Copyright: ๑ 2018 Ewart et al. This is an open access article distributed under the terms of the Creative Commons Attribution License, which permits unrestricted use, distribution, and reproduction in any medium, provided the original author and source are credited. 
Table 1. Cytochrome $b$ markers and their corresponding primers.

\begin{tabular}{|c|c|c|c|c|c|}
\hline Genetic marker for: & Primer name: & Primer sequence (5'-3'): & $\begin{array}{l}\text { Annealing temperature } \\
\qquad\left({ }^{\circ} \mathrm{C}\right):\end{array}$ & $\begin{array}{l}\text { Amplicon length* } \\
\text { (bp): }\end{array}$ & Reference: \\
\hline \multirow[t]{2}{*}{ Diceros bicornis (black rhino) } & $\begin{array}{l}\text { Rh_BR_FWD } \\
\text { (forward) }\end{array}$ & AАTCTGCСТАATCСТАСАAАTC & \multirow[t]{2}{*}{60} & \multirow[t]{2}{*}{222} & \multirow[t]{2}{*}{ This study } \\
\hline & Rh_BR_REV (reverse) & GGTTTCTAGGAAGGTGTAGG & & & \\
\hline \multirow[t]{2}{*}{$\begin{array}{l}\text { Ceratotherium simum (white } \\
\text { rhino) }\end{array}$} & $\begin{array}{l}\text { Rh_WR_FWD } \\
\text { (forward) }\end{array}$ & CCACTCATTCATCGATCTGC & \multirow[t]{2}{*}{60} & \multirow[t]{2}{*}{266} & \multirow[t]{2}{*}{ This study } \\
\hline & Rh_WR_REV (reverse) & TAATAGATACCGCGTCCTAC & & & \\
\hline \multirow{2}{*}{$\begin{array}{l}\text { Rhinoceros unicornis (Indian } \\
\text { rhino) }\end{array}$} & Rh_IR_FWD (forward) & TCTCACCCACTAGTTAAAATCA & \multirow[t]{2}{*}{60} & \multirow[t]{2}{*}{310} & \multirow[t]{2}{*}{ This study } \\
\hline & Rh_IR_REV (reverse) & AGGAAGGTGTAAGATCCATAG & & & \\
\hline \multirow[t]{2}{*}{ All rhino species } & RID_FWD (forward) & AACATCCGTAAATCYCACCCA & \multirow[t]{2}{*}{55} & \multirow[t]{2}{*}{274} & \multirow[t]{2}{*}[6]{} \\
\hline & RID_REV (reverse) & GGCAGATRAARAATATGGATGCT & & & \\
\hline \multirow[t]{2}{*}{ All rhino species } & Mac_FWD (forward & CAYTATACACCAGACACAACAAC & \multirow[t]{2}{*}{55} & \multirow[t]{2}{*}{226} & \multirow[t]{2}{*}{ This study } \\
\hline & Mac_REV (reverse) & TGAAYGCDGTGGCTATTAGRG & & & \\
\hline
\end{tabular}

*Amplicon lengths are inclusive of primer regions.

https://doi.org/10.1371/journal.pone.0202433.t001

\section{Reference}

1. Ewart KM, Frankham GJ, McEwing R, The DT, Hogg CJ, Wade C, et al. (2018) A rapid multiplex PCR assay for presumptive species identification of rhinoceros horns and its implementation in Vietnam. PLoS ONE 13(6): e0198565. https://doi.org/10.1371/journal.pone.0198565 PMID: 29902212 